\title{
Increasing social anxiety in the context of globalization of migration processes as a problem of international relations
}

\author{
Irina Britvina ${ }^{1}$, and Polina Shumilova ${ }^{1, *}$ \\ ${ }^{1}$ Ural Federal University, Yekaterinburg, Russia
}

\begin{abstract}
.
Research background: Increasing inward and outward labor migration flows between Central Asian countries and Russia are very significant for both sides. Migration processes in the Central Asian region play an important role in stabilizing international relations, because their economic, political and social results are important for all the countries in the region. The Russian Federation is one of the countries which receives the most immigrants, along with the United States, Germany, France and Canada. Migrants with different ethnicities from Central Asia constitute most of the migratory flows to Russia.

Purpose of the article: The authors aimed to analyze the growing social anxiety about the rising influx of migrants from Central Asian countries in Russia, as an indicator of the risk of developing damaging social processes. Methods: The authors draw their conclusions from the results of a questionnaire survey given to residents of Yekaterinburg in $2016(\mathrm{~N}=485)$ and $2019(\mathrm{~N}=476)$, and a comparison of comments on the internet from Russians in 2019 and 2020 about the behavior of migrants from Central Asian countries. The methods for analysis include a descriptive analysis, correlation analysis, content analysis, comparative analysis, words clustering analysis and quantitative word frequency calculation.

Findings \& Value added: The authors conclude that the increasing social anxiety from residents of Yekaterinburg about the rising influx of migrants from Central Asian has moved to the next stage of latent conflict, which R. Darendorff describes as the stage of "awareness of latent interests". The obtained results are important for the regulation of processes inter-country relations in the field of migration exchanges.
\end{abstract}

Keywords: migrants with different ethnicity; Russia; Central Asia; social anxiety; survey; content analysis

JEL Classification: $F 69 ; H 79 ; J 15$

\footnotetext{
* Corresponding author: polina_shumilova@mail.ru
} 


\section{Introduction}

Both sides are interested in increasing the flows of labor migration from Central Asian countries to Russia: the hosting and the sending countries. Migration processes in the Central Asian region play an important role in international relations due to the fact that their economic, political and social consequences are important for all countries of this region. Scientists connect the globality of migration processes with the qualification and educational characteristics of migrants $[1,2]$. Researchers believe that migrants contribute to the integration of their country into the world market, which may be especially important for the economic growth of developing countries [3]. The concept of the demographic development of the Russian Federation for the period up to 2025 suggests ensuring the migration growth to reach the level of more than 300 thousand people annually: migrants are considered as an important labor and demographic resource. The Central Asian countries contribute politically and economically to the increase in the labor migration flow to Russia, experiencing pressure on the labor market from the numerous young generation. A positive factor for these countries is also the monetary inflow from migrants working in Russia.

The Russian Federation is one of the world leaders in the foreign migrants' intake. The Sverdlovsk region is in the fifth place among other regions of Russia in terms of the number of incoming migrants. The largest migration flow comes from the countries of Central Asia. In 2019, the total number of migrants in the region made up 139 thousand.

Scientists believe that fears of "the invasion of others" serve as a verbal explanation of the emotional perception of migrants as aliens, uninvited guests [4]. Researchers write about the fears of "loss of resources" and "loss of one's own identity" on the part of the host community. These fears have a foundation. Studies show that the outflow of monetary funds over the background of their transfer to migrants' home countries reduces the wages of local workers [5]. Besides, one cannot deny the influence of migrants of different ethnicities on the weakening of identity of the host community [6]. In addition, the local population perceives this problem as negative. On the other hand, over the background of the growth of labor migration, positive changes in the development of the quality of human capital in the receiving country are not taken into account by the local population, although this fact has been proven [7]. Researchers studying the relationship of migrant employment problems with the ethnic characteristics of the labor force in a particular region note that show that diversity in terms of nationalities matters more than diversity based on parents' origins. Employment correlates positively with local labor market diversity, but negatively with neighborhood diversity. Immigrants tend to self-select into more economically dynamic areas [8].

During a period of the growing social tension, the risk of development of destructive social processes and conflicts is high. Social anxiety is an element of the social tension. In May 2020, the assessment of the level of anxiety of Russians became higher than the maximum level of the crisis period in the early 1990s. The current situation is long-term; it will continue after the epidemiological situation improves and restrictive measures are weakened, since its main driver — the deteriorating economic condition of Russians - will not disappear [9].

Bojana Blagojevic considers structural changes in society, accompanied by uncertainty, instability and fear, as the first stage in the development of interethnic conflicts [10]. When treating social anxiety as a special state of social consciousness and behavior, which is typical for conflict situations and accompanies them [11], it is important to understand that this state often finds a way out in the form of aggression. The danger that modern society faces is the difficulty of timely recognition and diagnosis of the first stages of the social conflicts development [12]. For example, researchers identify the problem of the emergence 
of conflicts in the field of management on the basis of cultural and language barriers as a result of the influx of migrants [13]. Scientists note that securing and maintaining employment is a key challenge for immigrants. Latent conflict potential on the part of the host community towards migrants can start to progress as a response to the events that should not have such impact (for example, the atmosphere of hostility towards migrants in the UK has significantly increased after the referendum on the membership in the European Union in 2016) [14; 15]. It is necessary to monitor constantly the nature of the interactions between the host community and the migrants with different ethnicities.

The authors aimed to analyze the growing social anxiety about the rising influx of migrants from Central Asian countries in Russia, as an indicator of the risk of developing damaging social processes.

\section{Methods}

Georg Simmel noted that interethnic conflict is a classic demonstration of "dispute" in the struggle to defend interests [16]. An important phenomenon that determines the conflict is the feeling of hostility of one social group towards another. Simmel considered it as a consequence of the "a priori instinct" and an inherent phase of the conflict behaviour.

Today the term "prejudice" is more often used in the study of interethnic relations. The prejudiced attitude in social interactions appears from different intergroup emotions based on the sense of threat [17]. This very sense of threat can go through transformation. In the times of crisis, prejudice can turn into hatred and hostility and lead to conflict.

Interethnic relations always have a conflict potential, since ethnicity is a form of social identity, based on culture and general emotions. It is important to remember that hatred towards other people is one of the oldest emotions.

An a priori feeling of prejudice towards migrants of different ethnicities from Central Asian countries on the part of Russians can contribute to the escalation of the latent phase of the conflict. Analysis of the verbal expression of the prejudiced attitude seems to be an effective indicator of the conflict state. We identified the following parameters demonstrating the potential for conflict and its state in relation to the host community for the analysis of the presented material.

1. The emphasis on the native culture in the statements, related to interethnic interactions, clearly signals the presence of cultural opposition. The presence of topics related to history and traditions is an indicator of comparing two states of society: without migrants from Central Asian countries and with them as a factor of the modern social order.

2. Statements, related to indicating the position adopted by the challenged social group. We have identified the statements associated with the concept of "work", following Simmel's typology and defining this conflict as a universal dispute of "domination and subordination" [18].

3. The presence of verbal positions that characterize a general negative attitude towards migrants of different ethnicities: fear, aggression, conflict, physical exclusion of migrants.

4. Mentioning the authorities in connection with the negative statements related to the migrants of different ethnicities is an indicator of the growing tension in the point of contact of social groups [19].

Internet commenting is an activity that makes it possible to freely express opinions on different subjects. That is why we have chosen a pool of comments to thematic issues on the Internet in order to identify the trend of the host community's attitude development towards migrants from Central Asian countries. 
On April 3, 2019, an interview with Professor I. B Britvina (Ural Federal University, Russia, Yekaterinburg) was posted on the all-Russian blogging platform Yandex.Zen [20]. The interview contained the results of studies with a conclusion about the claims of the Russian society towards migrants based on cultural differences. An interesting result for us, as researchers, was the very high activity of Russians in the comments (678 comments). Their content clearly indicated the general emotions of the host community regarding the migrants.

The analysis also included the comments to the article titled "Migrants Rebelled in Koltsovo: Special Forces Are on Duty at the Special Reception Center for Foreigners" on the popular information portal E1.ru in Yekaterinburg (Russia) [21]. The article was published on April 24, 2020, during the quarantine measures. The article got a significant pool of comments (128 units), characterized by high emotionality towards migrants from Central Asian countries. Both comment pools were analyzed as integral texts, since they are united by the general context of the Internet issue. Content analysis of the sets of comments was carried out using the definition of associations between words (Jaccard coefficient), clusterization and quantitative word frequency analysis.

Thus, the authors of the article base their conclusions on the results of the questionnaire surveys of Yekaterinburg citizens held in $2016(\mathrm{~N}=485)$ and in $2019(\mathrm{~N}=476)$, as well as on the results of the comparison of Internet comments posted in 2019 and 2020 regarding the behavior of migrants from Central Asian countries. Analysis methods: statistical and correlation analysis, content analysis, comparative analysis, words clustering analysis and quantitative word frequency calculation.

\section{Results}

The main characteristics of migrants from Central Asia influencing the character of their interactions with the host community are the different ethnicity, affiliation with a different culture and the civilizational lag. The results of our previous studies show the presence of a high cultural distance, subjectively felt by Russians, with migrants from Central Asian countries, and the presence of a threat from them. One can clearly observe the latent phase of the conflict, which is based on cultural distance [22]. In 2016, we identified latent conflict sentiments demonstrated by the host Russian community regarding migrants from this region. A survey of residents of Yekaterinburg showed that more than one half of the survey participants $(56.3 \%)$ consider the increasing number of migrants of different ethnicities to be a problem; $60.2 \%$ of respondents have a negative attitude towards migrants from Central Asian countries. In subsequent years, that prejudiced attitude towards migrants from Central Asian countries has transformed into open conflicts in a number of regions of Russia (for example, anti-migrant demonstrations in Yakutsk in 2019).

$76.0 \%$ of the respondents who have a negative attitude to the increasing number of migrants in Yekaterinburg consider this as a problem for the city. Among the respondents who do not have a clearly expressed position, only $28.7 \%$ of the respondents think the same. Among the respondents who have a positive attitude to the increasing number of migrants, only $18.6 \%$ consider this to be a problem for Yekaterinburg. Accordingly, less than one third of the respondents from Yekaterinburg (29.7\%) are used to the presence of a large number of migrants from Central Asian countries. Half of the respondents are only partially used to it (49.3\%), and one fifth cannot get used to it at all $(19.2 \%)$.

In 2019, the survey of Yekaterinburg citizens showed that conflict sentiments only intensified, despite the fact that the presence of migrants has already become habitual for the majority of respondents $(68.3 \%)$. Only $16.8 \%$ of respondents seek to interact (cooperate) with migrants. On the contrary, $9 \%$ of the respondents mentioned the desire for competition, and $13 \%$ - for the conflict with migrants. One third of Yekaterinburg 
residents are sure that migrants themselves provoke conflicts more often $(30.5 \%)$, and only $8 \%$ believe that conflicts are provoked by local residents. One fifth of the respondents $(21.4 \%)$ admitted that they had conflicts with visitors from Central Asia. Almost a third of Yekaterinburg residents do not seek to interact with them at all (27.9\%). 39.5\% of Yekaterinburg residents believe that the life in the city will become safer if there are no migrants. $20 \%$ of the respondents say that in such case, the city will experience positive changes.

The results of the content analysis of comments posted in 2019 show the highest frequency of expressions related to the Russian culture, social relations and the social structure of Russia. In addition, one can observe the domination of statements related to the problems of accepting migrants, building relationships with them, determination of their social position and role in the Russian society. In general, the reflections of the Russian citizens are focused on the problems of the host community in the context of the presence of migrants. The texts reveal the desire of Russians to build a new socio-cultural reality, where migrants play a subordinate role in the labor sphere. Yekaterinburg residents demonstrate a strong opinion that the cultural specificity of visitors from Central Asian countries does not fit in the Russian context.

The results of the analysis of the pool of comments posted in 2020 showed more clearly formulated claims of the Russian community — defending territorial resources through the deportation of migrants from the country. The statements contain a clear increase in the sense of danger presented by migrants. An explicit crystallization of claims against immigrants from Central Asian countries is revealed, accompanied by growing negativity and anxiety. The growth of the sentiments of Russians related to the necessity to determine the social position of migrants as subordinate can be clearly recorded. The cultural "otherness" of migrants from this region is highlighted by the appeals to Orthodoxy as a measure of the highest ethical values that are disrespected by migrants of different ethnicities. In this regards it is also important to mention the statements addressing the government and the authorities in the accusative sense.

A comparative analysis of the pool of comments published with a difference of one year demonstrates changes in the attitude of the host community towards migrants with different ethnicities from Central Asia. Amid the growing social anxiety, a transition from the latent stage of escalation of interethnic relations towards the conflict between the indicated social groups is obvious. Our earlier research also reported a high percentage of people feeling threatened by migrants from Central Asian countries. However, the fears were mainly based on prejudices related to the migrants' foreign culture. Migrants were perceived as "subordinates" (in accordance with Simmel's "dispute" typology).

The results of the analysis of comments posted in 2020 related to migrants of different ethnicities in Russia cause greater concern. The clear articulation of the claims of the Russian citizens to migrants reflects the processes corresponding to what R. Darendorff calls the second stage of the conflict development, which consists in "direct crystallization, that is, the awareness of latent interests, organization of quasi-groups into actual groupings [23]. Important indicators of the aggravated conflict are: transformation of the Russian community's attitude towards migrants of different ethnicities from Central Asian countries into negative emotions, fear for the safety, dissatisfaction with the actions of the authorities regarding migration regulation, the desire to deport migrants from the country. The authors conclude that the increasing social anxiety from residents of Yekaterinburg about the rising influx of migrants from Central Asia has moved to the next stage of latent conflict, the stage of "awareness of latent interests". The obtained results are important for the regulation of processes inter-country relations in the field of migration exchanges. 


\section{Discussion and conclusion}

As the number of migrants of different ethnicities grows, the problem of migrantophobia in all receiving countries is becoming more acute. Although official statistics do not provide basics for some fears associated with the presence of migrants, the opinion of members of the host community, along with objective factors, can be a catalyst for the migrantophobia outspread. The general background for strengthening this kind of sentiments is the growing uncertainty of the social system due to the multimillion influx of foreign citizens with an unclear social status, which causes changes in ordinary rules, norms of business and everyday relationships, and forces the local population to adapt to rapid changes.

How likely is the progression of the worst-case scenario of conflict sentiments in relation to migrants of different ethnicities from Central Asian countries on the part of the host Russian community? What will be the impact of this tense situation, characterized by an increased indicator of social anxiety among Russians? What events can become dramatic drivers of the increasing conflict and what preventive measures should be taken? What impact will this have on the international situation in the region?

Bojana Blagojevic notes that ethnic conflict arises when a certain set of factors and conditions is formed: a massive structural crisis; the presence of historical memories of interethnic offences; institutional factors that promote ethnic intolerance; manipulating historical memory in order to evoke fear, resentment and hatred of "others"; interethnic competition for rights and resources. Analyzing the attitude of Russians towards migrants, we can note the presence of the following factors that coincide with those mentioned above:

1. Structural social crisis (problems in the economy, social and political sphere of Russian society);

2. Negative memories based on tragic events called the "genocide of Russians" during the collapse of the USSR;

3. Institutional factors associated with the problems of integrating migrants into the "cultural field" of the Russian community;

4. Interethnic competition for resources and rights.

Thus, the situation that is developing around the relations between migrants from Central Asian countries and the host Russian community looks ready for use by destructive forces, and presents a threat to the international situation.

The reported study was funded by RFBR according to the research project № 19-011-00467.

\section{References}

1. Biavaschi, C., Burzynski, M., Elsner, B., Machado, J. (2020). Taking the skill bias out of global migration. Journal of Development Economics, 142, 102317.

2. Burzynski, M., Deuster, C., Docquier, F. (2020). Geography of skills and global inequality. Journal of Development Economics, 142, 102333.

3. Rapoport, H. (2016). Migration and globalization: what's in it for developing countries? International Journal of Manpower, 37(7), 1209-1226.

4. Moukomel', V.I. (2005). Facets of intolerance (migrantpliobias, ethnophobias). Sociological Studies, 2, 56-72. (In Russ.)

5. Olney, W.W. (2015). Remittances and the wage impact of immigration. The Journal of Human Resources, 50, 694-727.

6. Drobizheva, L.M. (2018). Civil Russian identity: dynamics and potential in the consolidation of a multi-ethnic society. In: Ethnic and Religious Diversity in Russia. Moscow: Institute of Ethnology and Anthropology. (In Russ.) 
7. Hémet, C., Malgouyres, C. (2018). Diversity and employment prospects: Neighbors matter! Journal of Human Resources, 53(3), 825-858.

8. Cattaneo, C., Fiorio, C.V., Peri, G. (2015). What happens to the careers of European workers when immigrants "take their jobs"? The Journal of Human Resources, 50(3), 655-693.

9. Club of Regions: Federal Expert Network (2020, May 7). The level of anxiety and fears of Russians: Results of an expert online panel on the all-Russian survey of VCIOM. Retrieved from : http://clubrf.ru/images/files/5eb3bfd935d37.pdf?utm_source=Uralweb.ru\&utm_medium=CPC\&u tm_campaign=ssylki_v_news (In Russ.)

10. Blagojevic, B. (2009). Causes of ethnic conflict: A conceptual framework. Journal of Global Change and Governance, 3(1), 1-25.

11. Naryshkina, M.V. (2017). Social tension in the Zabaykalsky Krai as a factor of political risk in the activities of the political party "United Russia". World Politics, 1, 66-80. (In Russ.)

12. Karjakin, V.V. (2014). Modern crises and conflicts: features, scenarios and prevention. Problems of the National Strategy, 4(25), 136-151. (In Russ.)

13. Dwertmann, D.J.G., Kunze, F. (2020, June 9). More than meets the eye: The role of immigration background for social identity effects. Retrieved from : https://journals.sagepub.com/doi/abs/10.1177/0149206320929080

14. Guma, T., Jones, R.D. (2019). "Where are we going to go now?" European Union migrants' experiences of hostility, anxiety, and (non- )belonging during Brexit. Population, Space and Place, 25(1), 2198.

15. Lulle, A., King, R., Dvorakova, V., Szkudlarek, A. (2019). Between disruptions and connections: "New" European Union migrants in the United Kingdom before and after the Brexit. Population, Space and Place, 25(1), 2200.

16. Simmel, G. (1908). Soziologie: Untersuchungen über die Formen der Vergesellschaftung. Leipzig: Verlag von Duncker \& Humblot.

17. Abeywickrama, R., Laham, S.M., Crone, D. (2018). Immigration and receiving communities: The utility of threats and emotions in predicting action tendencies toward refugees, asylum- seekers and economic migrants. Journal of Social Issues, 74(4), 756-773.

18. Stepanenkova, V.M. (1999). "The struggle of all for all": Georg Simmel's theory of conflict. Sociological Journal, 3/4, 149-164. (In Russ.)

19. Britvina, I. (2019, April 13). Sociologist explained the nature of Russian rejection of migrants from Central Asia. Retrieved from https://zen.yandex.ru/media/urfu/cociolog-obiasnila-prirodu-nepriiatiia-rossiianamimigrantov-iz-centralnoi-azii-5cb184f3cc595b00b3b8501e (In Russ.)

20. Rumyantsev, D. (2020, April 27). Migrants rebelled in Koltsovo. (In Russ.) Retrieved from : https://www.e1.ru/news/spool/news_id-69115936.html

21. Britvina, I, Mogilchak, E., Savchuk, G. (2018). Attitudes of the citizens of the Ural megalopolis towards migrants of different ethnicities. In T. Löster \& T. Pavelka (Eds.), The 12th International Days of Statistics and Economics: Conference Proceedings (pp. 239-246). Prague: Libuše Macáková, Melandrium.

22. Levada Analytical Center (Levada-Center) (2019, September 17). Xenophobic mood in Russia grows for the second year in a row (In Russ.). Retrieved from : https://www.levada.ru/2019/09/18/ksenofobskie-nastroeniya-v-rossii-rastut-vtoroj-god- 
podryad

23. Dahrendorf, R. (1961). Gesellschaft und Freiheit. Zur soziologischen Analyse der Gegenwart. München: R. Piper \& Co Verlag. 